\title{
Qualidade Visual do Patrimônio Arquitetônico Eclético na Paisagem Urbana da Área Central de Santa Cruz do Sul: O Impacto das Mídias Exteriores
}

\author{
Diego Hennig Lovato ${ }^{1}$ \\ Franciele Schuster Gehlen ${ }^{1}$ \\ Maicon Pinto de Moraes ${ }^{1}$ \\ Luiz Carlos Schneider ${ }^{2}$
}

\section{RESUMO}

O projeto de pesquisa: "Qualidade Visual do Patrimônio Arquitetônico Eclético na Paisagem Urbana da Área Central de Santa Cruz do Sul: O Impacto das Mídias Exteriores" teve como principal objetivo realizar um diagnóstico referente ao impacto visual causado pelos diferentes elementos de publicidade utilizados nas edificações do período eclético da arquitetura. Parte-se dos pressupostos de que os elementos de publicidade, em seu excesso, ocasionam a perda da legibilidade das edificações patrimoniais pela população. Por outro lado, as alterações de identidade visual dos imóveis ocorrem também em conjunto com outros processos como os de sua readequação funcional e descaracterização física. Este artigo compreende uma descrição sintética da metodologia utilizada para desenvolver a pesquisa, bem como os principais resultados finais obtidos ao longo dos dois anos de estudo (2012 e 2013) e que estão relacionados ao uso atual e original das edificações, ao conceito de legibilidade (integridade física e estado geral de conservação externa) das obras e a avaliação geral dos diferentes níveis de impactos causados pelas mídias.

Palavras-chave: Arquitetura Eclética. Mídias Exteriores. Patrimônio Arquitetônico. Santa Cruz do Sul.

\begin{abstract}
Research: "Qualidade Visual do Patrimônio Arquitetônico Eclético na Paisagem Urbana da Área Central de Santa Cruz do Sul: O Impacto das Mídias Exteriores" had as the main objective to establish a diagnostic related to the visual impact caused by different elements of publicity used in the buildings during the eclectic architectonic period. It begins with the assumption that the excess of publicity elements result in the loss of the patrimonial heritage visibility However, the shifts in the visual identity occurred simultaneously in sync with other processes including functional reconditioning and loss of physical characteristic. This article aims to comprehend a synthetic description of methodology used to develop the research, as well as the main results gathered in over two years, which are related to the current and original use of the patrimony, according to the concept of legitimacy (physical integrity and general statement of external conservation) of the buildings and the general evaluation of different impacts caused by the media.
\end{abstract}

Key-words: Eclectic Architecture. Billboard Medias. Architectural Heritage. Santa Cruz do Sul.

${ }^{1}$ Alunos do Curso de Arquitetura e Urbanismo da Universidade de Santa Cruz do Sul.

2Professor do Departamento de Engenharia, Arquitetura e Ciências Agrárias na Universidade de Santa Cruz do Sul.<luizcs@unisc.br> 


\section{INTRODUÇÃo}

O patrimônio arquitetônico eclético da área central urbana de Santa Cruz do Sul, delimitada nesta pesquisa entre as ruas Coronel Oscar Rafael Jost, Gaspar Silveira Martins, Senador Pinheiro Machado e Carlos Trein Filho, tem grande valor histórico e artístico para a região do Vale do Rio Pardo e para o estado do Rio Grande do Sul. Esta relevância é atestada em publicações de autores como KELLER (2001) e WINK (2000) e está registrada também em diferentes pareceres técnicos e levantamentos patrimoniais produzidos pelo município e pela Universidade de Santa Cruz do Sul- UNISC. As edificações pertencentes ao período eclético da arquitetura (final do século XIX até aproximadamente as primeiras três décadas do século XX), integridade física das edificações bem como de sua visibilidade. Contudo, a dinâmica econômica do centro urbano e dos seus processos de concentração espacial e de refuncionalização caracteriza-se pelas necessidades constantes de readequação dos imóveis em termos de novos usos e adaptações construtivas. Neste aspecto, por exemplo, as edificações patrimoniais acabam por receber diferentes tipos de intervenções, muitas das quais descaracterizam, em diferentes níveis, a legibilidade do projeto original. Outra questão recorrente é a necessidade das atividades comerciais e de prestação de serviços utilizarem anúncios publicitários de todos tipos e que em excesso podem ocasionar o fenômeno da poluição visual. As mídias exteriores produzem impactos singulares (em nível de leitura da edificação), mas em seu conjunto tem também a capacidade de influenciar drasticamente a identidade da paisagem urbana. Neste aspecto, é importante ressaltar a importância de legislações relacionadas às formas de regulação da publicidade e de seus impactos nos espaços abertos públicos.

A pesquisa se desenvolveu ao longo de dois anos e em duas etapas distintas. A primeira etapa esteve relacionada à revisão bibliográfica sobre os temas de patrimônio cultural, arquitetura eclética e mídias exteriores. Utilizaram-se autores como: FILHO (2004), DONDIS (2007), BARBAN (2001) e CHOAY (1999). A sequência de atividades abrangeu as ações de reconhecimento e localização do patrimônio arquitetônico eclético da área central urbana de Santa Cruz do Sul por meio de pesquisa documental (pareceres técnicos e inventários patrimoniais do município) e pesquisa histórica. Foi realizada também uma pesquisa de campo com levantamento das edificações que apresentam características próprias da arquitetura eclética produzindo-se mapas temáticos de uso e ocupação patrimoniais. Já na segunda etapa, objeto mais especifico deste artigo, a pesquisa concentrou-se na análise de legibilidade das edificações. Este conceito, relacionado à percepção visual, e à capacidade de 
leitura do objeto arquitetônico, foi desenvolvido por meio de seu desdobramento em ações distintas, mas, que estão inter-relacionadas entre si. A primeira constituiu-se a partir da identificação da tipologia da obra e de seu aspecto original e atual. As descaracterizações resultantes dos processos de refuncionalização das obras acabam por refletir-se em seu estado de integridade física e também de conservação do imóvel. Por fim, avaliaram-se também a utilização das mídias exteriores e os seus impactos relacionados às alterações de visibilidade da edificação. Deste conjunto de processos, produziu-se um relatório final, ou diagnóstico com níveis distintos de impactos produzidos pelas mídias exteriores bem como de legibilidade geral das edificações. A sistematização das informações foi realizada com a produção de gráficos, tabelas, relatórios técnicos e de mapas temáticos como os de localização geral do patrimônio, de integridade física e de localização das edificações ecléticas com mídias externas. Por fim, apresentam-se conclusões e considerações finais.

\section{CARACTERIZAÇÃO DA ARQUITETURA}

O levantamento patrimonial compreendeu, conforme o Gráfico 1, um total de 140 edificações ecléticas, sendo que destas 43 estão registradas como bens oficialmente inventariados, ou seja, possuem valores históricos, culturais e/ou artísticos-estilísticos reconhecidos e catalogados em publicações específicas. Neste sentido, um aspecto importante a ser destacado é o fato de que muitos dos imóveis não inventariados possuem igual relevância de valores arquitetônicos dos bens inventariados, sendo classificados na pesquisa como levantamento A e totalizando 23 edificações. Estas edificações, juntamente com o levantamento B (arquitetura eclética mais recorrente), totalizam noventa edificações e não são reconhecidas como patrimônio. Como resultado, observou-se que no período de 2012 a 2013 sete imóveis foram demolidos, o que comprova que uma significativa parte da arquitetura eclética urbana de Santa Cruz do Sul está desprotegida legalmente em um contexto de rápida transformação da paisagem urbana. 


\section{Gráfico 1 - Total de prédios da arquitetura eclética}

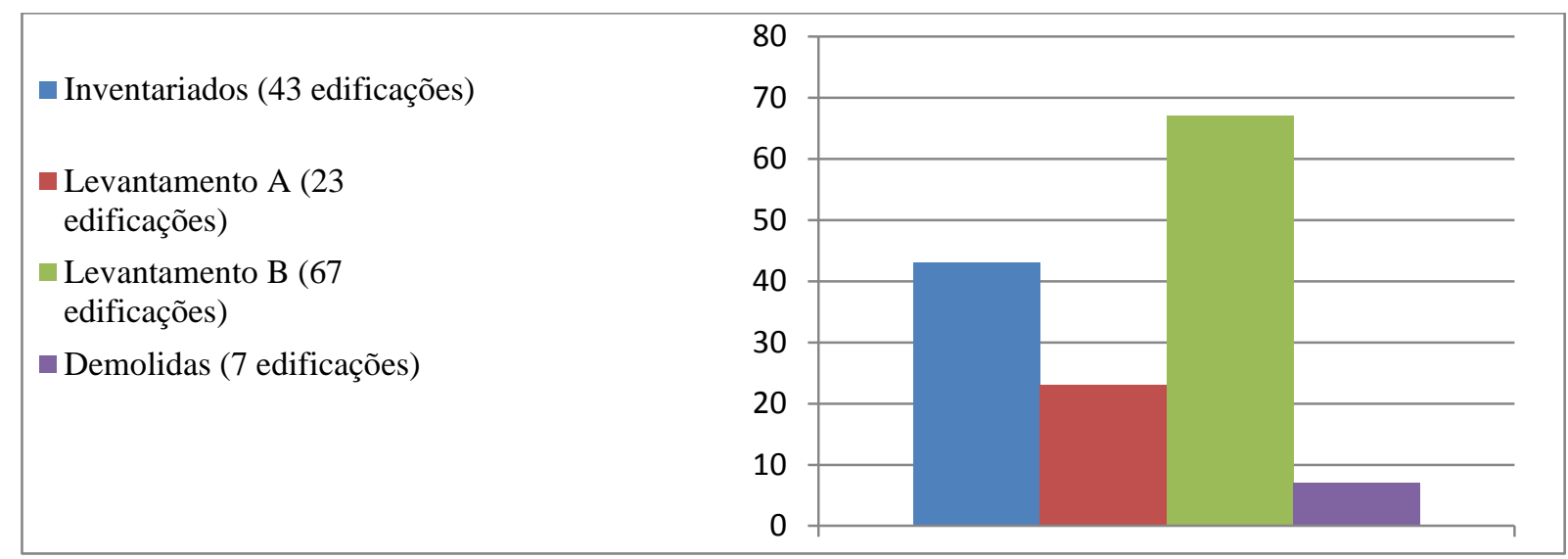

Fonte: Elaborado pelos autores com base nos dados da pesquisa, 2012 - 2013.

A transformação da paisagem urbana é influenciada pelo rápido crescimento econômico da cidade de Santa Cruz do Sul e as edificações patrimoniais estão sujeitas a processos de substituição em diferentes níveis (de total até parcial). As intervenções físicas nos imóveis são causadas principalmente pelas mudanças de usos, o que pode ser observado nos Gráficos 2 e 3 relacionado ao uso original e atual do bem patrimonial. Neste caso, percebe-se que a maior parte das edificações que eram originalmente residenciais, hoje, apresentam o uso comercial. O mesmo ocorre com a substituição dos usos de tipologias industriais para comerciais, ao mesmo tempo em que ocorreram significativas substituições de uso de edificações religiosas ou institucionais para a predominância do uso comercial e de prestação de serviços.

\section{Gráfico 2 - Uso original das edificações ecléticas}

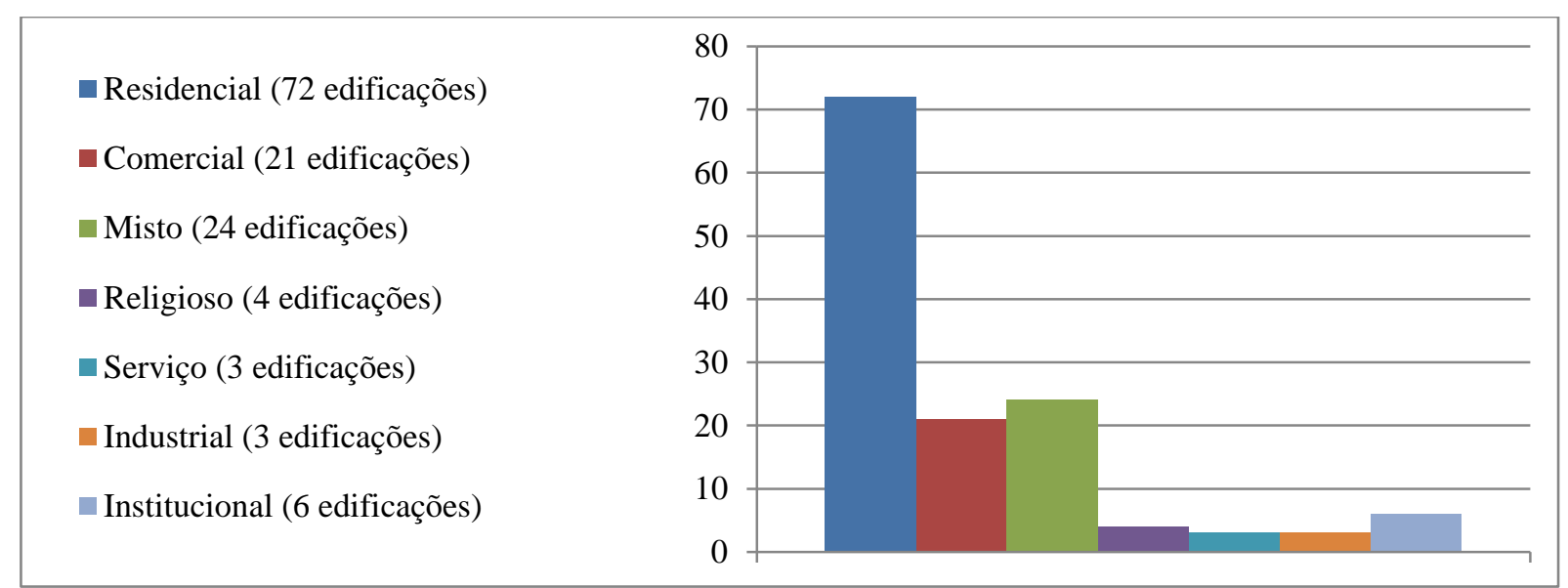

Fonte: Elaborado pelos autores com base nos dados da pesquisa, 2012 - 2013. 


\section{Gráfico 3 - Uso atual das edificações ecléticas}

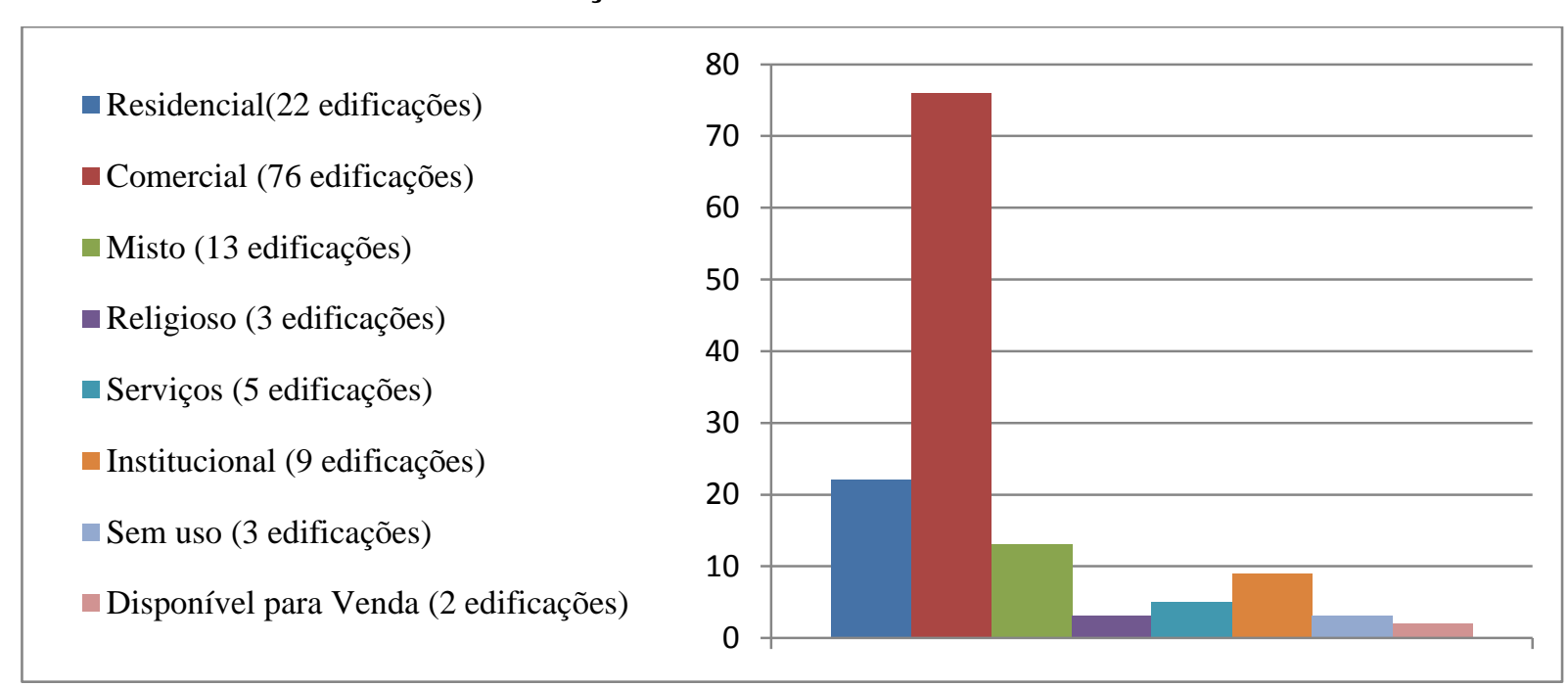

Fonte: Elaborado pelos autores com base nos dados da pesquisa, 2012 - 2013.

Em síntese, pode-se afirmar que a predominância atual de usos comerciais acarreta a necessidade de readequações das edificações ecléticas por meio de reformas e adaptações a novas exigências funcionais que, recorrentemente, tem sérias implicações para a integridade física e visual das edificações.

\section{LEGIBILIDADE: INTEGRIDADE FÍSICA, ESTADO DE CONSERVAÇÃO E MÍDIAS EXTERIORES}

\subsection{INTEGRIDADE FÍSICA DA OBRA}

As condições de legibilidade da edificação, em termos da sua arquitetura e do projeto original, estão, em um primeiro momento, sujeitos a integridade física e ao estado geral de conservação da obra. A integridade física da obra revela as condições gerais de preservação da edificação, de seu estado original ou então do que é percebido como alterado, incompleto. Isto porque as obras apresentam diferentes níveis de intervenções e descaracterizações causados por reformas ou readequações que alteram ou suprimem os elementos originais da arquitetura. Neste sentido, quanto maiores forem as intervenções e descaracterizações realizadas nas obras, maiores serão os prejuízos de sua leitura em relação à harmonia, ordem e equilíbrio visual da edificação. Destaca-se aqui que não está sendo realizada uma avaliação destes aspectos em relação à qualidade artística ou arquitetônica da obra em si, mas sim em relação às intenções do seu projeto original. 


\section{Gráfico 4 - Legibilidade da edificação: Integridade Física}

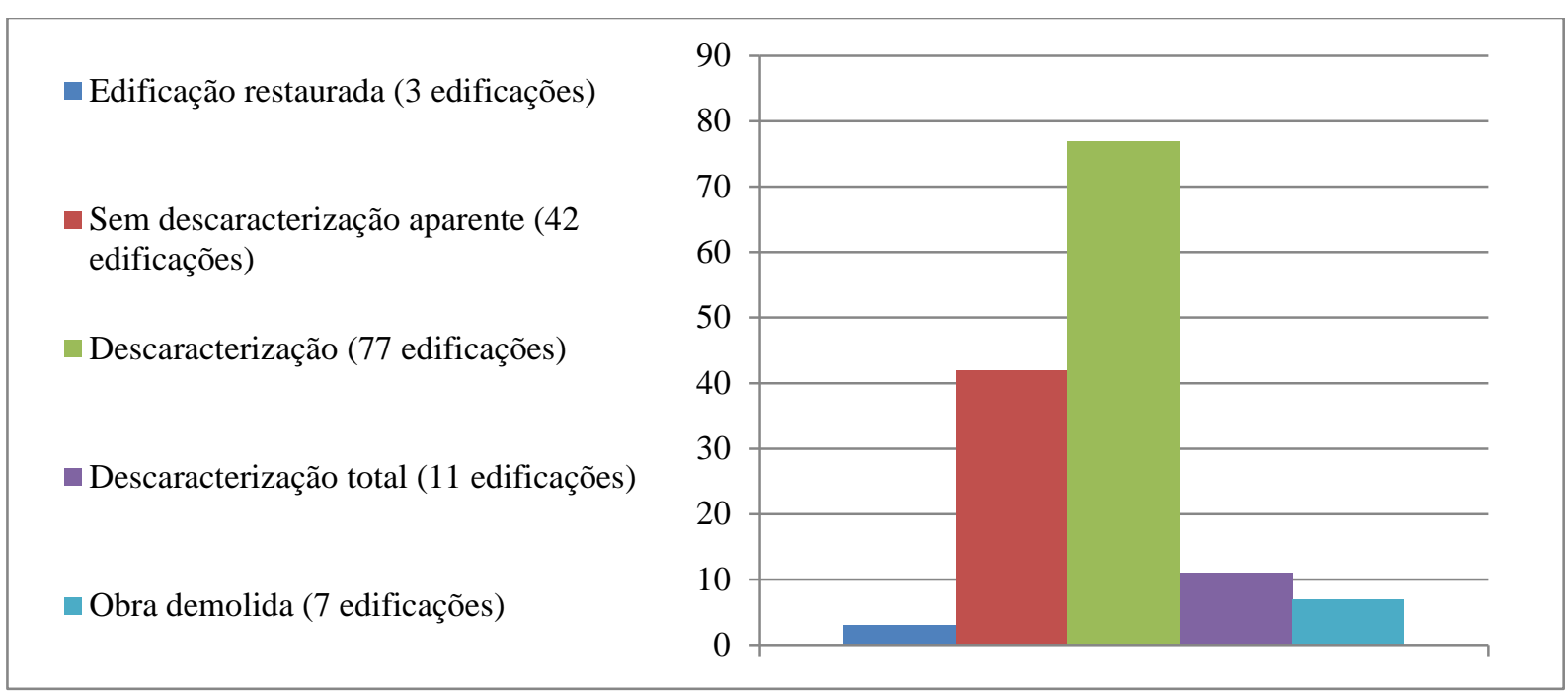

Fonte: Elaborado pelos autores com base nos dados da pesquisa, 2012 - 2013.

Neste sentido, a primeira etapa foi a de isolar o objeto de estudo (edificação) enquanto cenário de utilização da mídia e identificando o comprometimento das condições originais de percepção visual. A classificação em níveis de descaracterizações físicas, em ordem decrescente da pior condição de legibilidade do projeto original para a melhor situação de clareza na percepção visual, deu-se a partir dos critérios sinteticamente descritos abaixo:

- Alta descaracterização: comprometimento da leitura original da edificação ocasionada por substituição de volumes, intervenções de grande escala na obra, na qual todas as alterações no seu conjunto causam grande impacto visual e são normalmente de difícil retorno à situação original;

- Média descaracterização: eliminação ou substituição parcial dos elementos de sua arquitetura original, causando a sensação de incompletude, perda ou de transformação visual perceptível da obra. Porém há condições de reversão da situação para nível inferior;

- Baixa descaracterização: poucas alterações que no seu conjunto não causam perda da leitura da edificação ou que tem pequeno impacto visual capaz de ser absorvido pelo conjunto. É passível de retorno à situação original;

- Sem descaracterização aparente: clareza absoluta na legibilidade da obra ou do projeto arquitetônico; 


\section{Gráfico 5 - Níveis de descaracterização}

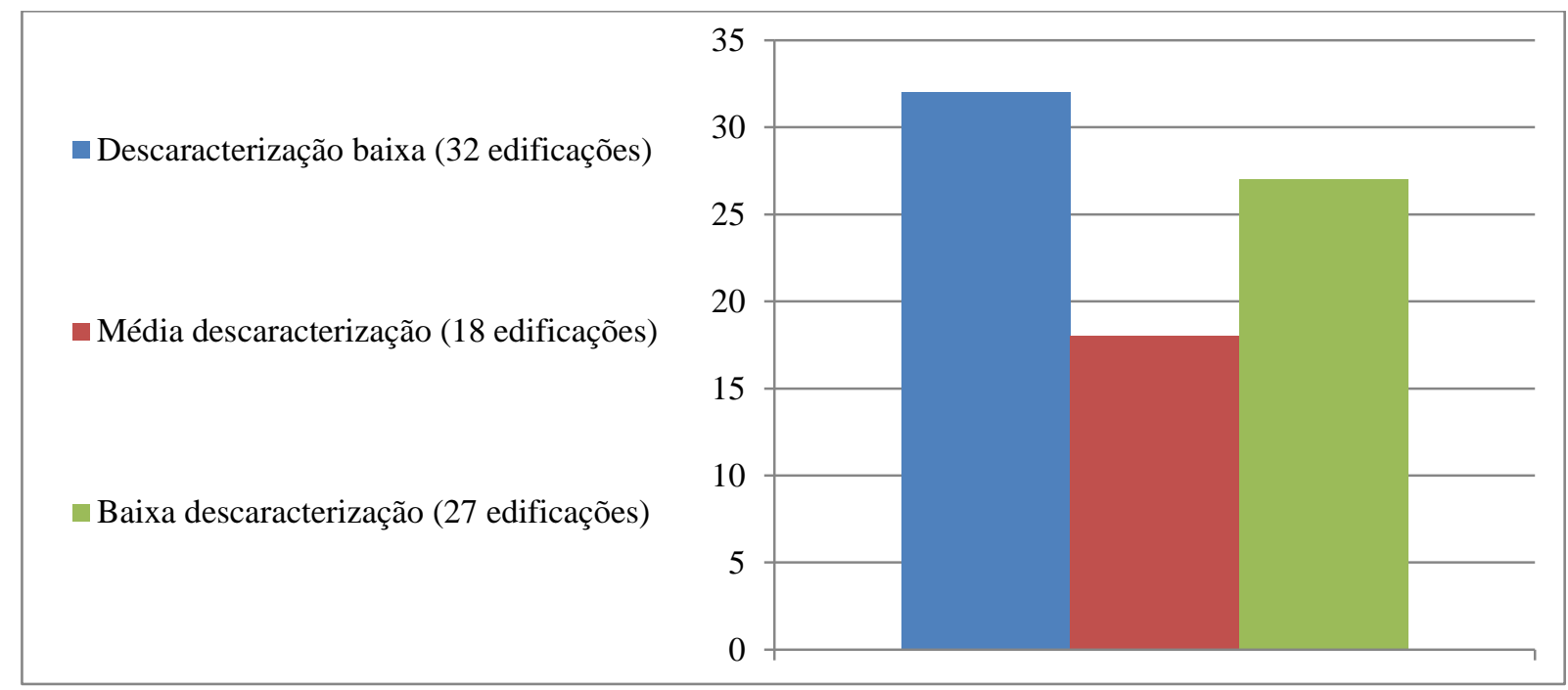

Fonte: Elaborado pelos autores com base nos dados da pesquisa, 2012 - 2013.

A maior parte das edificações ecléticas analisadas $(55,3 \%$ das edificações) apresentaram níveis altos e médios de descaracterizações. Observou-se também que onze casos apresentaram o nível de descaracterização total da obra, onde há presença de poucos elementos originais da arquitetura eclética.

\subsection{ESTADO DE CONSERVAÇÃO DA OBRA}

Outro componente importante para legibilidade da edificação está relacionado às condições do estado geral de conservação da edificação. Esta avaliação foi realizada considerando-se o nível de percepção das condições de limpeza e de manutenção ou conservação das fachadas voltadas ao espaço público. Neste aspecto classificaram-se as obras quanto aos seguintes níveis de conservação:

- Excelente/Muito bom: pintura nova ou bem recente, excelente conservação de materiais e revestimentos das fachadas exteriores em seu conjunto. Não apresenta trincas, rachaduras, descolamento de revestimento e outras patologias aparentes;

- Bom: pintura recente, bom estado de conservação das esquadrias e outros elementos arquitetônicos, não apresentando sinais visuais de descuido da edificação. Pode apresentar pequenas trincas ou rachaduras em reboco do tipo 
superficial observáveis unicamente quando se está muito próximo à edificação, eventuais e raras manchas causadas por descoloramento da tinta ou bolor;

- $\quad$ Regular: pintura antiga com mais de dez anos ou pintura mal realizada, algumas patologias aparentes mais visíveis externamente como rachaduras, trincas, manchas nas fachadas, eventuais descolamentos de superfícies do reboco, necessidade maior de conservação de elementos aparentes como esquadrias, persianas, telhados, saliências, alto relevos e similares;

- $\quad$ Ruim: precariedade ou mau estado de conservação geral dos materiais de esquadrias ou fachadas, pintura em mau estado com desgaste, descoloramento, descolamentos de reboco, significativo número de patologias facilmente observáveis, manchas nas fachadas e estado de conservação degradado, incluindo eventualmente perda de material.

- Precário: correspondente às sensações de abandono, ruínas, comprometimento estrutural perceptível;

Conforme o Gráfico 6, observamos que de um total de 140 edificações as fachadas possuem, em sua maioria, bom ou muito bom estado de conservação, havendo preocupação com a visibilidade e identidade visual do empreendimento, por motivos comerciais.

\section{Gráfico 6 - Estado geral de conservação externa da obra}

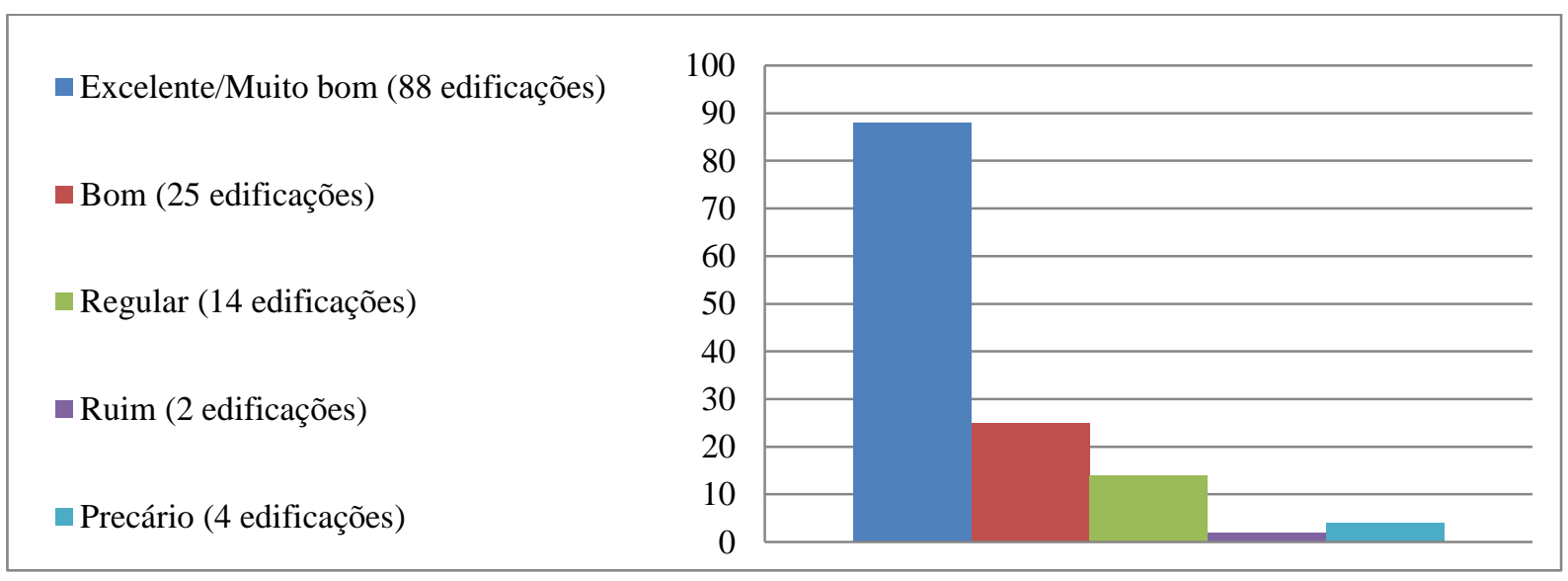

Fonte: Elaborado pelos autores com base nos dados da pesquisa, 2012 - 2013.

Por meio da avaliação conjunta destes dois itens: integridade física e estado geral de conservação externa da obra são obtidas as condições gerais de legibilidade da obra arquitetônica. Constitui-se em uma avaliação da qualidade física da edificação patrimonial e 
também em um importante elemento de análise para entender as condições de percepção de sua integridade e identidade visual. A manutenção de suas condições originais (linhas, planos, volumes, texturas) e o seu estado de conservação são fundamentais para distinguir a qualidade desta percepção visual enquanto plano de fundo que é utilizado para sobreposições das mídias.

\subsection{MÍDIAS EXTERIORES}

Em relação à existência de Mídias Exteriores constatou-se, como aponta o Gráfico 7, que a maior parte das 133 edificações pertencentes à arquitetura eclética apresentam elementos de publicidade como painéis, letreiros, adesivos, entre outros. Esta informação corresponde proporcionalmente aos dados levantados sobre os atuais usos que são predominantemente comerciais e mistos (atividade conjunta residencial e comercial).

\section{Gráfico 7 - Prédios da arquitetura eclética com existência de mídia externa}

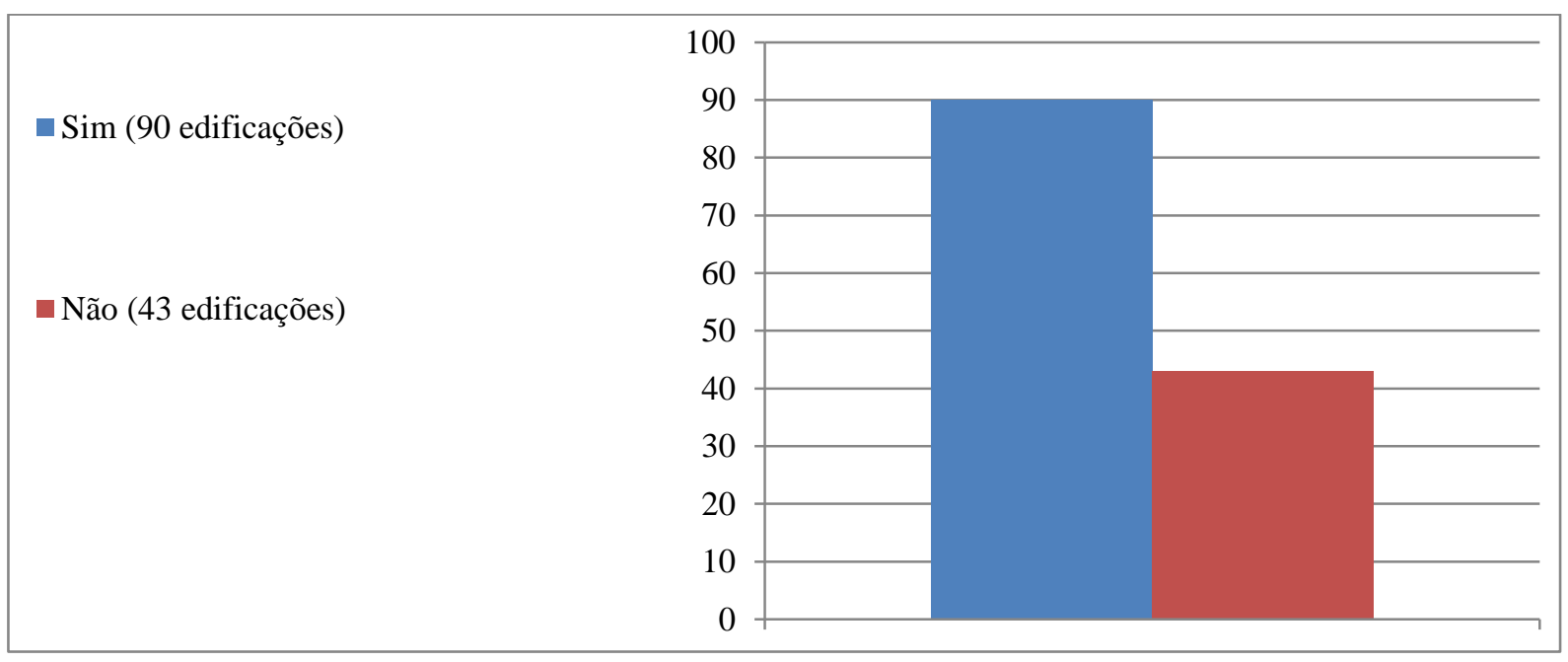

Fonte: Elaborado pelos autores com base nos dados da pesquisa, 2012 - 2013.

Constatou-se, conforme o Gráfico 7, um total de 90 edificações que apresentam mídia exterior, dos quais 32 constituem arquitetura inventariada. Conforme apresentado no Gráfico 3, há predominância absoluta dos usos comerciais e mistos (associação de uso residencial e comercial) que utilizam mídias exteriores e que acabam refletindo as necessidades de readequação e adaptação dos imóveis às novas necessidades.

Em relação à integridade física das 90 edificações que apresentam mídia exterior, e conforme o Gráfico 8 , constatou-se que $42 \%$ dessas edificações apresentam alta legibilidade 
com baixa ou nenhum tipo de descaracterização aparente. Entretanto, a maior parcela, representando $48 \%$ dos imóveis analisados, apresentam altas e médias descaracterizações. Ressaltando ainda, a presença de dez casos classificados como descaracterização total, pois pertencem ao que se denominou de reminiscências arquitetônicas, ou seja, há presença de poucos elementos originais reconhecíveis da arquitetura eclética.

\section{Gráfico 8 - Integridade física das edificações com mídia exterior}

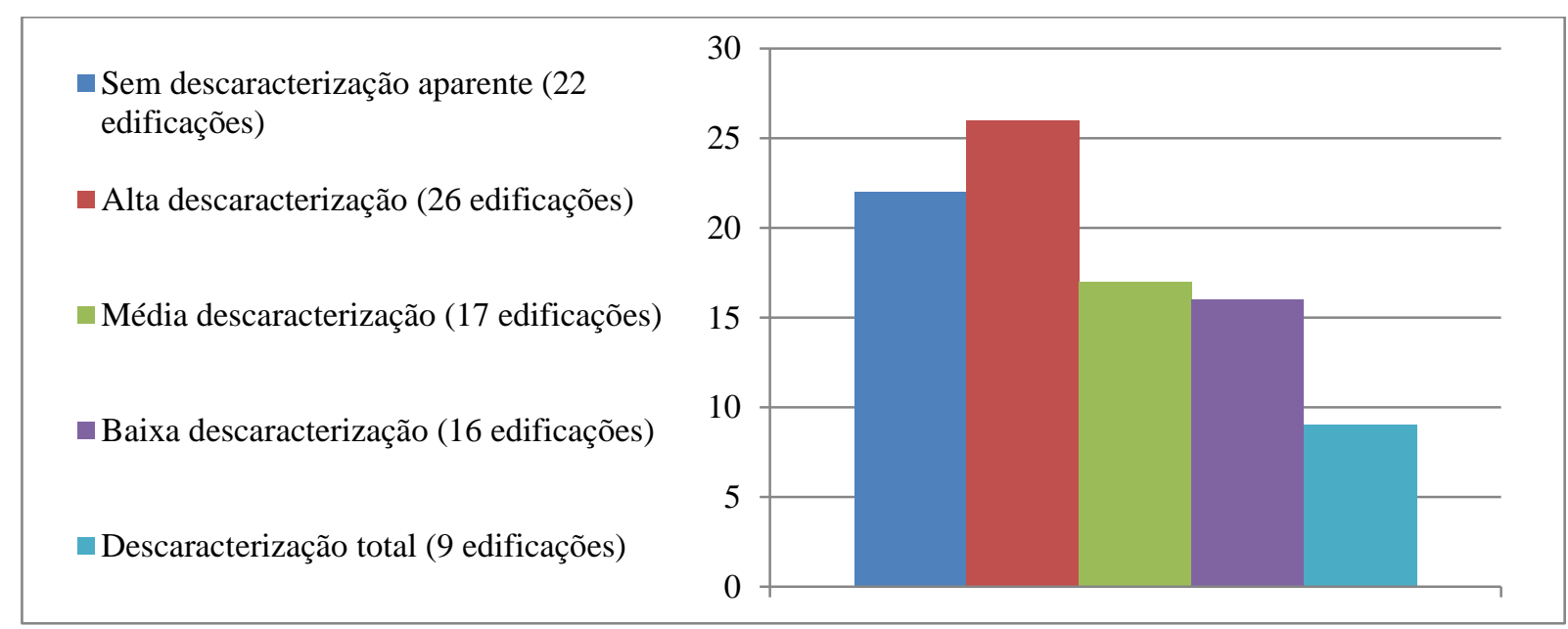

Fonte: Elaborado pelos autores com base nos dados da pesquisa, $2012-2013$.

Em relação ao estado geral de conservação, da mesma forma que na análise geral das 133 edificações, também há prevalência de um excelente e muito bom estado de conservação das fachadas, conforme mostra o Gráfico 9. Esta é uma indicação positiva comprovando que há preocupação com a visibilidade do empreendimento por motivos evidentemente comerciais, mas também sem descartar a percepção afetiva de muitos usuários ou proprietários de imóveis. 


\section{Gráfico 9 - Estado de conservação externa das obras}

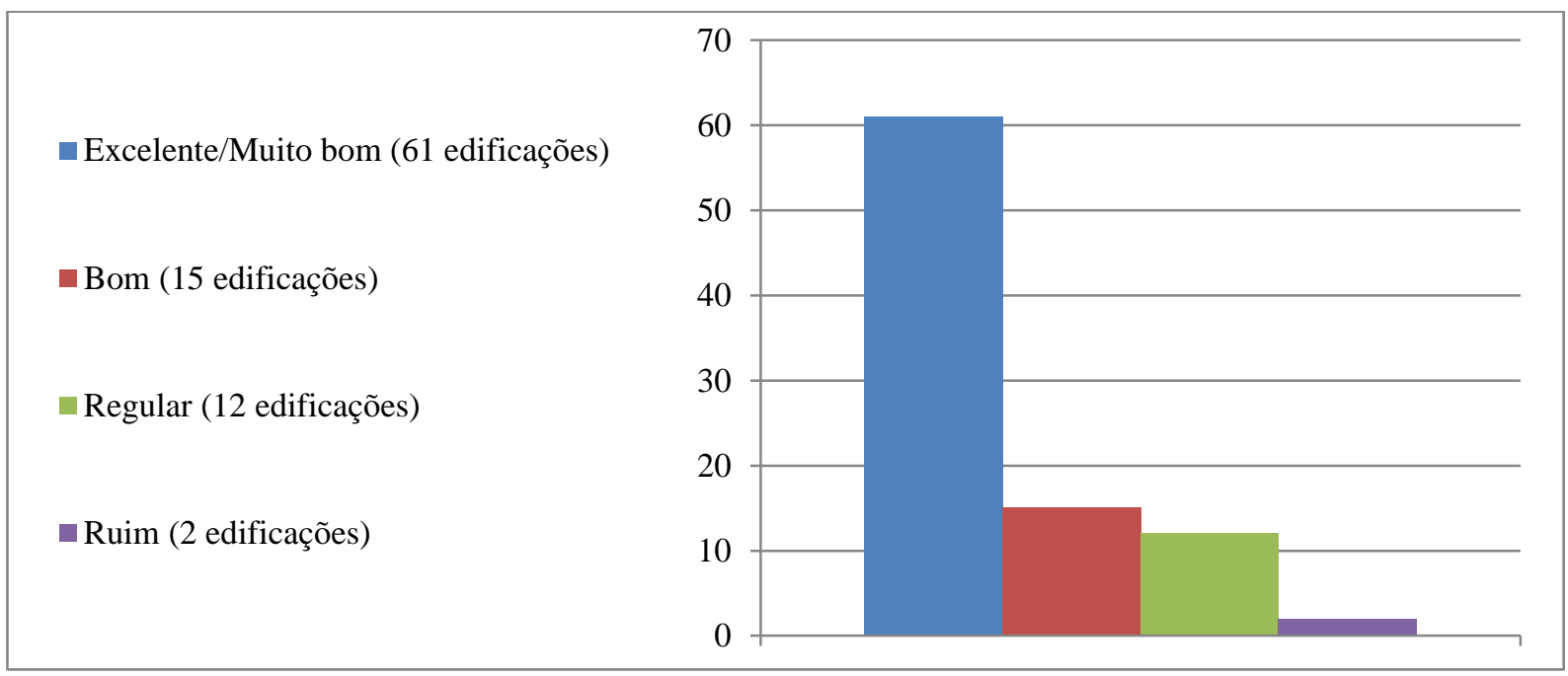

Fonte: Elaborado pelos autores com base nos dados da pesquisa, 2012 - 2013.

\section{AVALIAÇÃO DOS IMPACTOS}

$\mathrm{Na}$ etapa de avaliação do impacto das mídias exteriores foi utilizado parte da metodologia proposta por Gomes Filho (2009) derivada das principais leis da Gestalt. Desta forma as mídias foram avaliadas em relação a categorias tais como: harmonia, ordem, equilíbrio e contraste e em seu conjunto por meio dos conceitos de unidade, segregação, fechamento, boa continuação, semelhança e proximidade.

Para a análise realizaram-se os seguintes procedimentos: identificação e avaliação das unidades de estudo (edificação e mídias); e em um segundo momento, foram realizadas as interpretações das unidades e de sua relação enquanto conjunto indissociável de percepção da imagem do objeto por meio da análise compor meio de utilização das leis da Gestalt e aplicando as categorias conceituais de harmonia, equilíbrio e contraste. Atribuiu-se também, por meio da aplicação de valores em matriz, um índice de qualidade para a pregnância formal de cada edificação: baixo, médio e alto.

Estas avaliações foram realizadas também em duas situações distintas: arquitetura eclética com mídias e arquitetura inventariada com mídias. 
Gráfico 10 - Níveis de impacto visual das mídias na arquitetura eclética

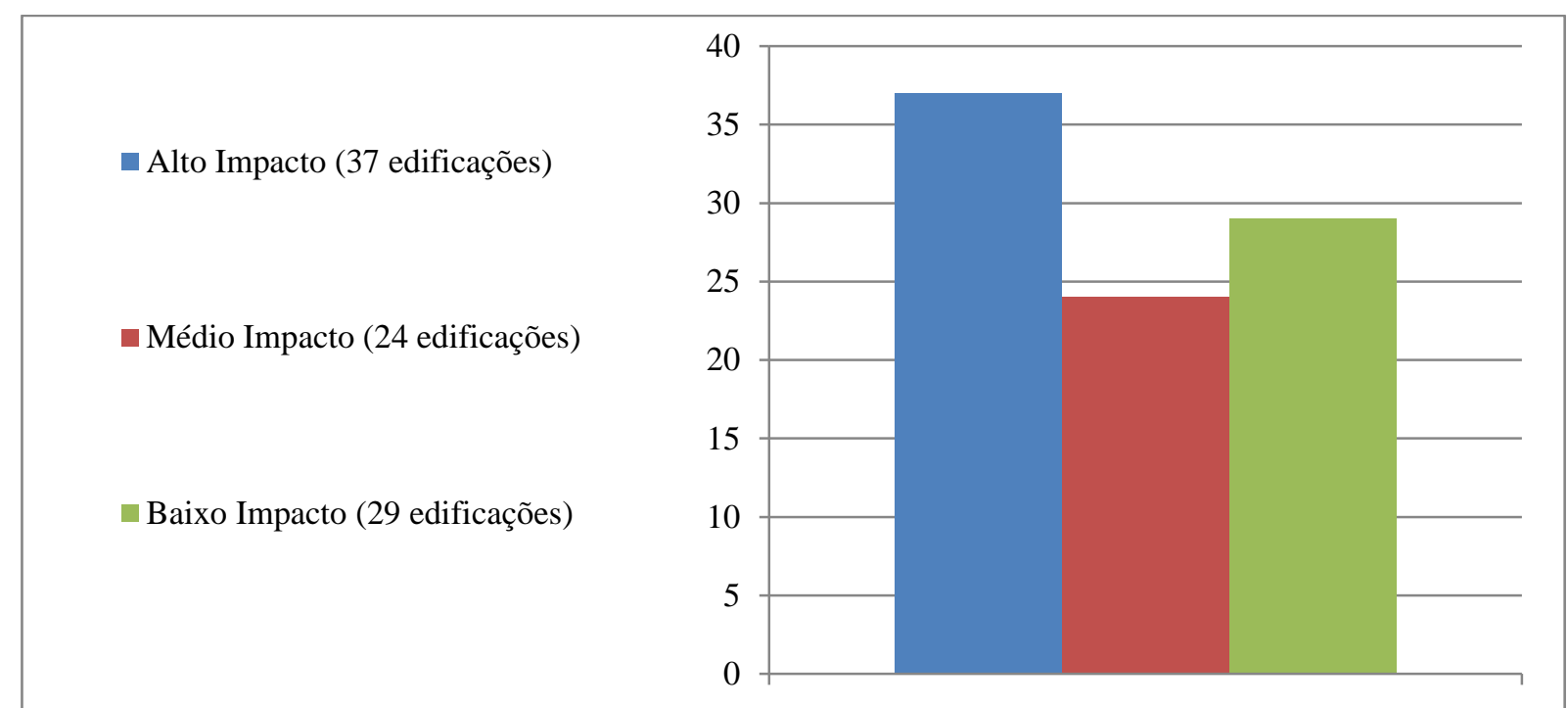

Fonte: Elaborado pelos autores com base nos dados da pesquisa, $2012-2013$.

Os valores mais altos refletem a maior perda de legibilidade das edificações atingindo $41 \%$ do total das obras.

\section{Gráfico 11 - Níveis de impacto visual das mídias na arquitetura inventariada}

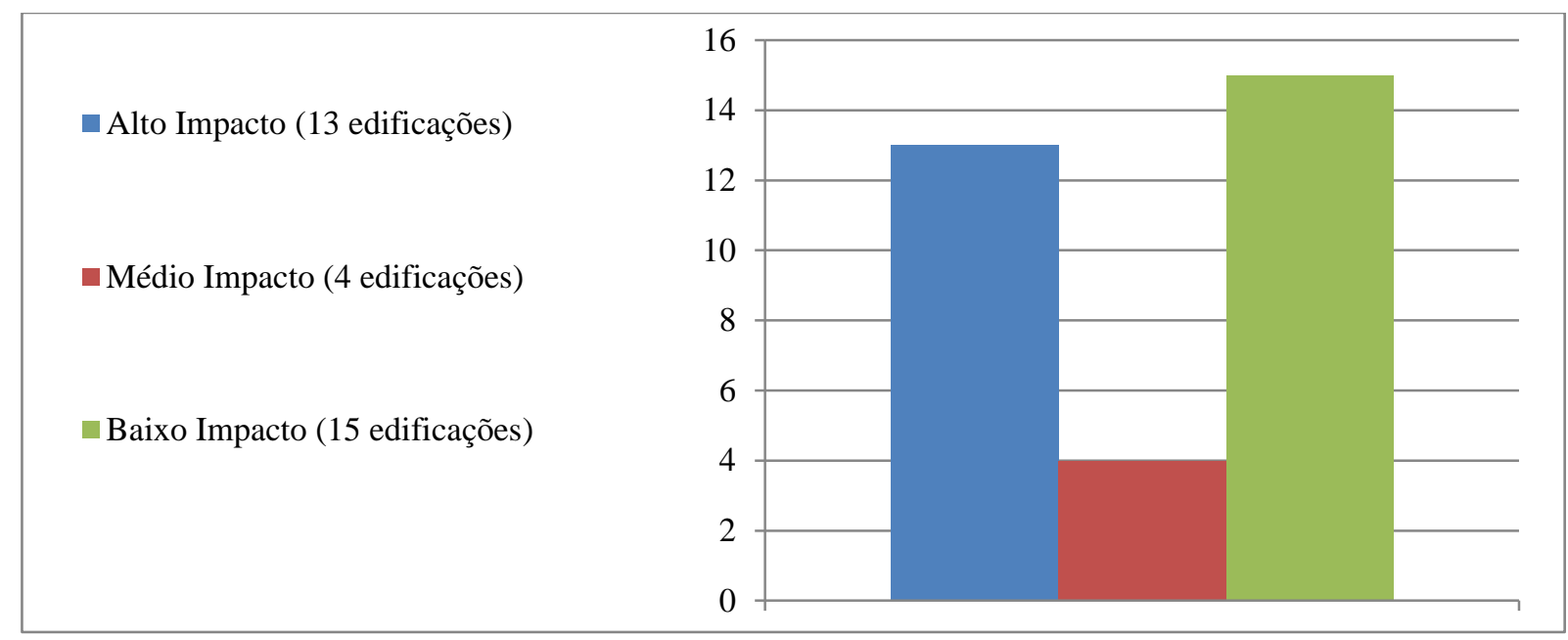

Fonte: Elaborado pelos autores com base nos dados da pesquisa, 2012 - 2013.

Em relação à arquitetura eclética inventariada (32 edificações), e conforme o gráfico, observa-se que as edificações com alto impacto visual atingem o mesmo percentual da classificação geral, ou seja, $41 \%$. 


\section{CONCLUSÃO}

O levantamento dos 133 prédios da arquitetura eclética no centro urbano da cidade de Santa Cruz do Sul - Rio Grande do Sul, contribuiu para a identificação e avaliação geral de um patrimônio arquitetônico que é fundamental para a manutenção da identidade e da memória da comunidade local. O rápido crescimento da cidade e as transformações espaciais da área central ocasionam mudanças de usos das edificações patrimoniais. Somam-se também outros fatores como necessidades de conservação, manutenção, adequações tecnológicas, funcionais ou simplesmente modernizações de caráter estético dos imóveis que acabam ocasionando processos de descaracterizações em diferentes níveis. Estes processos atingem a maior parte das edificações analisadas (55\% dos imóveis) e, no seu limite, implicam em perda total da qualidade artística e estética (7,8\% dos imóveis). Registram-se ainda 7 edificações demolidas no curto espaço de tempo (5\% dos imóveis) desta pesquisa.

Não há na lei, também, qualquer indicação relacionada à efetiva implementação de instrumentos relacionados à manutenção da identidade e da qualidade visual das edificações. A lei abre inclusive possibilidades de reformas que comprometem a legibilidade das edificações, em menor ou maior grau, desde que estas sejam apreciadas e aprovadas pelo Conselho Municipal de Planejamento Urbano. Como resultado da precariedade legal, observamos o aumento dos processos de descaracterização do patrimônio da cidade.

Com a seleção das edificações e avaliação dos níveis de legibilidade das mesmas, constatou-se que as descaracterizações consideradas altas (perda de identidade da obra) e as de descaracterizações totais (perda irreversível) chegam a um percentual de $39 \%$ ou 35 imóveis. Em outras palavras, praticamente mais de um terço das edificações com mídias exteriores já apresentam graves problemas relacionados à legibilidade da obra e de sua identidade original. Este fator, aliado aos processos de transformação urbana, indica que a "invisibilidade" de um patrimônio que não é mais reconhecido visualmente torna-o mais suscetível ao atual ritmo de demolições.

Os gráficos referentes ao impacto visual das mídias exteriores apresentam também resultados preocupantes para a integridade visual de preservação do patrimônio eclético. Tanto a arquitetura eclética inventariada quanto a não inventariada apresentam mais da metade das edificações com percentuais de colocação de mídias classificados como de alto e médio impacto, ou seja, as duas situações com maiores prejuízos da qualidade visual por meio da má utilização das mídias exteriores aliadas a situações em alto grau. Este percentual é um pouco menor para a arquitetura inventariada (53\%), mas expõe claramente a falta de 
valorização do patrimônio arquitetônico e a despreocupação com a qualidade visual, revelando também a ausência e omissão de controles legais.

É por este motivo que alguns casos mais graves de impactos de mídias exteriores e de descaracterizações estão registrados em prédios inventariados. Constatou-se que, a exceção de poucos casos, não há preocupação com aprovação de projetos de comunicação visual para imóveis de valor artístico e histórico. Essas decisões de projeto ficam sob responsabilidade do próprio empreendedor que não possui conhecimento técnico, muito menos algum tipo de orientação ou regra legal para a preservação visual de seu imóvel.

\section{REFERÊNCIAS}

ARGAN, G. C. História da Arte como história da cidade. São Paulo: Martins Fontes, 1992.

BARBAN, A. M. et. al. A essência do planejamento de mídia. São Paulo: Nobel, 2001.

CHOAY, F. A alegoria do patrimônio. Lisboa: Edições 70 Ltda, 1999.

CÓDIGO DE DEFESA DO CONSUMIDOR. Lei 8.078 de 11/09/90. Brasília, Diário Oficial da União, 1990.

DONDIS, D. A. Sintaxe da linguagem visual. São Paulo: Martins Fontes, 2007.

GIACOMINI FILHO, G. Consumidor versus propaganda. São Paulo: Summus, 1991.

GOMES FILHO, J. Gestalt do objeto: sistema de leitura visual da forma. São Paulo: Escrituras, 2004.

KELLER, M. R. Santa Cruz do Sul e sua Arquitetura Eclética. 2001. 262 f. Dissertação (Programa de Pós-Graduação de Desenvolvimento Regional - Mestrado e Doutorado)Universidade de Santa Cruz do Sul, Santa Cruz do Sul, 2001.

LEITE, M. A. Destruição ou desconstrução? Questões da paisagem e tendências de regionalização. São Paulo: Editora Hucitec, 1994.

LYNCH, K. A imagem da cidade. São Paulo: Martins Fonte, 1997.

NÚCLEO DE GESTÃO PÚBLICA. Inventário do Patrimônio Arquitetônico da área central urbano de Santa Cruz do Sul, pesquisa do Curso de Arquitetura e Urbanismo, Universidade de Santa Cruz do Sul - UNISC em parceria com a Prefeitura Municipal de Santa Cruz do Sul, 2006.

PREFEITURA MUNICIPAL/ SECRETARIA DE PLANEJAMENTO DE SANTA CRUZ DO SUL/ SOCIEDADE ALEMÃ DE COOPERAÇÃO TÉCNICA BRASIL ALEMANHA GTZ. Levantamento Patrimonial, 1986. 
SCHULTZ, V. Trabalho de levantamento com a Prefeitura Municipal, 2008.

WEIMER, G. Arquitetura Erudita da Imigração Alemã no Rio Grande do Sul. Porto Alegre: EST Edições, 2004.

WINK. R. Santa Cruz do Sul e sua Evolução Urbana. 2000. 269 f. Dissertação (Programa de Pós-Graduação de Desenvolvimento Regional - Mestrado e Doutorado) Universidade de Santa Cruz do Sul, Santa Cruz do Sul, 2000.

\section{Como citar este documento:}

LOVATO, Diego Hennig et al. Qualidade Visual do Patrimônio Arquitetônico Eclético na Paisagem Urbana da Área Central de Santa Cruz do Sul: O Impacto das Mídias Exteriores. Revista Jovens Pesquisadores, Santa Cruz do Sul, v. 6, n. 1, jun. 2016. ISSN 2237-048X. Disponível em: <https://online.unisc.br/seer/index.php/jovenspesquisadores/article/view/7286>. Acesso em: ... doi:http://dx.doi.org/10.17058/rjp.v6i1.7286. 